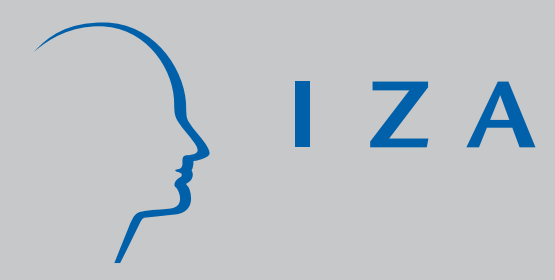

IZA DP No. 2862

A Simple Theory of Industry Location and Residence Choice

Rainald Borck

Michael Pflüger

Matthias Wrede

J une 2007 


\title{
A Simple Theory of Industry Location and Residence Choice
}

\author{
Rainald Borck \\ University of Munich \\ and DIW Berlin \\ Michael Pflüger \\ University of Passau, \\ DIW Berlin and IZA \\ Matthias Wrede \\ RWTH Aachen University \\ and CESifo \\ Discussion Paper No. 2862 \\ June 2007 \\ IZA \\ P.O. Box 7240 \\ 53072 Bonn \\ Germany \\ Phone: +49-228-3894-0 \\ Fax: +49-228-3894-180 \\ E-mail: iza@iza.org
}

Any opinions expressed here are those of the author(s) and not those of the institute. Research disseminated by IZA may include views on policy, but the institute itself takes no institutional policy positions.

The Institute for the Study of Labor (IZA) in Bonn is a local and virtual international research center and a place of communication between science, politics and business. IZA is an independent nonprofit company supported by Deutsche Post World Net. The center is associated with the University of Bonn and offers a stimulating research environment through its research networks, research support, and visitors and doctoral programs. IZA engages in (i) original and internationally competitive research in all fields of labor economics, (ii) development of policy concepts, and (iii) dissemination of research results and concepts to the interested public.

IZA Discussion Papers often represent preliminary work and are circulated to encourage discussion. Citation of such a paper should account for its provisional character. A revised version may be available directly from the author. 


\section{ABSTRACT}

\section{A Simple Theory of Industry Location and Residence Choice*}

This paper provides a simple theory of geographical mobility which simultaneously explains people's choice of residences in space and the location of industry. Residences are chosen on the basis of the utility which mobile households obtain across locations. The spatial pattern of industry is determined by the location decision of a scarce essential factor of production which seeks to obtain the highest possible economic return. Our theory comprehends applications to commuting and physical capital mobility. Referring to the decline in mobility costs, we are able to explain that long-distance commuting and foreign direct investment have increased and that industrial activity has become more concentrated both within as well as across countries.

JEL Classification: F12, F21, F22, R12, R23

Keywords: agglomeration, labour mobility, capital mobility, industry location, migration, commuting

Corresponding author:

Michael Pflüger

Lehrstuhl für Außenwirtschaft und Internationale Ökonomik

Universität Passau

Innstraße 27

D - 94032 Passau

Germany

E-mail: michael.pflueger@uni-passau.de

\footnotetext{
* We would like to thank Jens Südekum and Thomas Mathä as well as seminar participants in Dortmund, Innsbruck, Konstanz and Munich for helpful comments.
} 


\section{Introduction}

Mobility is a key feature of our times. Chroniclers of globalisation such as Thomas Friedman $(1999 ; 2006)$ provide picturesque accounts of how nations and regions are increasingly tied together. The political shifts and initiatives and the revolutions in communication, trade and mobility costs underlying this dramatic increase in the geographical mobility of economic activity have also been documented more prosaically (e.g. Baldwin and Martin, 1999). Apart from historically unprecedented levels of international trade, the mobility of physical capital (via foreign direct investment and multinational enterprises) is a particularly well-documented facet of the current wave of globalization. Moreover, significant reductions in travel costs and innovations in commuting technologies have greatly increased the mobility of people in the form of commuting. ${ }^{1}$ For example, the development of highspeed trains has substantially reduced long-distance commuting costs over the last decades in Japan and Europe. ${ }^{2}$ Finally, people have also become more mobile in the choice of their residences which is guided by a variety of needs and considerations.

Trade, the mobility of physical capital and long-distance commuting imply that the location of production can be separated from the location of consumption and from the location of residence. Of course, this general insight forms the commonplace basis of the theories of international trade, urban economics and economic geography. However, in analysing phenomena such as trade, capital mobility or commuting, these theories narrow down the range of choices considerably. Trade theory takes the locations of consumption and residence as given. Urban economics either takes the location of production (e.g. a central business district) as given and focusses on the choice of residences or it proceeds just inversely (the von Thünen tradition). The new economic geography allows for the mobility of production and residences but it typically ties these together (e.g. the core periphery model of Krugman, 1991). Interestingly enough, even though physical capital mobility

\footnotetext{
${ }^{1}$ The same does not hold true for migration which today is not higher than during the 'first wave of globalisation' at the end of the 19th century (Baldwin and Martin, 1999). In fact, migration has been found to be the 'great absentee' in the current wave of globalization, mostly because of the pre-existing political barriers (Faini et al., 1999).

${ }^{2}$ The number of interregional commuters, commuting distances and cross-border commuting in the OECD have increased (see OECD, 2005; MKW, 2001; Mathä and Wintr, 2007; Vermeulen, 2003). For instance, in Germany about $17 \%$ of commuters commute more than $25 \mathrm{~km}$ one-way and $5 \%$ commute more than $50 \mathrm{~km}$ (Statistisches Bundesamt, 2005). Commuting activity is even higher in Japan, the UK, Canada and Australia as compared to the Eureopean Union (OECD, 2000; MKW, 2001).
} 
and long-distance commuting allow for a separation of the locations of production and of residence, as yet there is no systematic analysis which endogenises these two decisions simultaneously. Conspicuously lacking is a more general theory of mobility. ${ }^{3}$

This paper provides such a theory in a simple model of industry location and residence choice. We examine geographical mobility in a two-region model with agglomeration effects. Individuals choose their residence on the basis of a comparison of the utilities they obtain across the two regions and which are affected by incomes, local goods prices and local housing prices. The spatial pattern of industry, on the other hand, is determined by the location decision of a scarce essential factor of production which seeks to obtain the highest possible economic return.

In one application of our theory, the scarce essential factor consists of physical capital, which is owned by the individuals. Capital may either be installed at the chosen location of residence or at the alternative distant location. Income derives to individuals in the form of capital rents which are assumed to be repatriated if capital is installed abroad. In another application this essential factor is the skill embedded in the individuals. They provide their skill either at the location of residence they have chosen, or by way of commuting, at an alternative distant location. Their income then consists of the skilled wage which is derived as a scarcity rent in one of the two regions.

Capital relocation or commuting occur from the low-rent or low-wage region to the highrent or high-wage region. Apart from the residence choice, our theory thus comprehends two phenomena which we observe in our age of mobility: first, the mobility of physical capital whereby capital owners may reside at a location different from the one where the capital is installed and profits are repatriated and, second, long-distance commuting, whereby people make use of high-speed trains or other commuting technologies to bridge the distance between the locations of production and residence.

We shall assume that individuals buy and consume the goods in the region where they reside. ${ }^{4}$ Though deliberately parsimonious, this set-up provides a non-trivial theory of

\footnotetext{
${ }^{3}$ There is a literature at the interface of urban economics and the new economic geography which focusses on commuting - i.e., the separation of the location of production and consumption/residences within cities (e.g., Krugman and Livas Elizondo, 1995; Tabuchi, 1998; Murata and Thisse, 2005; Tabuchi and Thisse, 2005). One paper on intercity commuting that we are aware of is Ogura (2005), but there is no agglomeration force in his model.

${ }^{4}$ This assumption is the natural one when production and residences are separated through capital mobility. With commuting it becomes a distinct possibility that commuters spend some of their income at their place of work. We leave this straightforward extension of our theory for future work.
} 
industry location and residence choice, since all factors guiding the location of industry and residences depend on the level of economic activity and on mobility costs (trade costs, commuting or capital relocation costs) and since there are feedback effects between the location of industry and the location of residences.

We view the contributions of the paper as threefold. First, we provide a unified theory of geographical mobility, where the location of industry and residences are jointly determined. This theory delivers a rich set of implications which can be subjected to empirical scrutiny. For example, by referring to the general decrease in mobility costs (i.e. trade, commuting and capital relocation costs), our analysis is broadly able to explain that long-distance commuting and foreign direct investment have increased and that industrial activity has become more concentrated. Second, our analysis contributes to the ongoing research program of the new economic geography which seeks to understand the fundamental forces determining the location of economic activity. In particular, we are able to shed light on the question how the market equilibrium's propensity to agglomerate is affected by commuting or the mobility of physical capital. Third, and related to the previous point, our analysis builds a bridge between two well-known models widely used in the new economic geography: the analytically tractable agglomeration model with mobile skilled labour of Forslid and Ottaviano (2003) and the model with mobile physical capital developed by Martin and Rogers (1995). ${ }^{5}$ The Forslid-Ottaviano model assumes that skilled labour is mobile but workers must live where they work; the Martin-Rogers model, while allowing for physical capital mobility, differs from ours by assuming that capital owners are mobile. Essentially, our model combines these two approaches.

The paper proceeds as follows. In the next section we provide an informal preview of our analysis and its central results. We present the model in section 3. The choice of workplace and of residences are analysed in section 4, and the last section concludes the paper.

\section{A preview of the analysis and central results}

As already noted, our theory of industry location and residence choice allows for applications involving the mobility of physical capital, or, alternatively, long-distance commuting.

\footnotetext{
${ }^{5}$ The first of these has also been termed the 'footloose entrepreneur model' whilst the second is sometimes referred to as the 'footloose capital model' (see Baldwin et al, 2003).
} 
It will prove to be convenient to cast the analysis in terms of one of these applications, only, the other application simply commanding a suitable reinterpretation. Even though it may appear most natural to focus on physical capital mobility, the following analysis will highlight long-distance commuting simply because this allows us to exhibit the breadth of our approach. However, it should be clear that, by appropriate choice of words, the analysis can immediately be recast in terms of the mobility of physical capital. This simply requires to substitute 'mobile capital owners' for mobile workers, 'relocation of capital' for long-distance commuting, 'capital relocation costs' for commuting costs and 'capital rent' for the wage of the skilled in the following.

We perform the analysis in a sequence of stages involving first, prohibitively high commuting costs, second, positive (but not prohibitive) commuting costs and, finally, zero (negligible) commuting costs and at each stage we highlight the role of trade costs. ${ }^{6}$

When commuting costs are prohibitively high, the choice where to live is the same as the choice where to work. Hence, we are in the agglomeration model without commuting which underlies our analysis. This model has equilibria with dispersion for low and high trade freeness and either partial or full agglomeration for intermediate levels of trade freeness. This result is due to the interaction of four fundamental location forces which are familiar from the new economic geography: market size (the 'demand linkage'), the local price index of consumer goods (the 'supply linkage'), local competition (the 'competition effect') and congestion in the housing market. The joint location of industry and residences reflects the relative strength of these forces at different stages of trade integration: at low levels of trade freeness, the dispersive effect of local competition is dominant whereas at high levels of trade freeness the location decision is determined by housing prices, again implying a dispersed outcome. At intermediate ranges of trade freeness, the supply linkage and the demand linkage induce an agglomeration of economic activity.

These results are altered by long distance commuting which makes it possible to separate residences from work places (i.e. industry location). The commuting decision and, hence, the location of industry, is determined by industrial wages which depend on market size and on the state of local competition. The place of residence is chosen on the basis of the local prices of goods and housing and on the trade-off between local wages and the commuting cost. The two choices are connected, however: the residence choice affects the size of the local market and the pattern of industry location affects local price levels. Due

\footnotetext{
${ }^{6}$ For illustrative purposes, we treat the case of prohibitive commuting costs first, then zero commuting costs and positive commuting costs at the end.
} 
to these feedback effects we obtain a non-trivial theory of industry location and residence choice with a rich set of outcomes.

What then are the effects of commuting on the agglomeration of residences and industry, to what extent does commuting occur and what is the commuting pattern? Intuitively, one might expect that with commuting one can live in small cities where housing is cheap and work in large cities where wages are high, so that commuting leads to less agglomeration of residences. In fact, what we find is that residences are generally more agglomerated than without commuting, and that the pattern of commuting differs from this expectation in certain cases.

These results are obtained in starkest form in the model with zero commuting costs. Here, we find that, except at a range of intermediate trade costs, long distance commuting fosters agglomeration of residences. Moreover, the pattern and the net extent of commuting are related to the level of trade costs. If trade freeness is low, residences are fully agglomerated and industry is partly dispersed whilst the opposite holds true at high levels of trade freeness. Hence, commuting indeed takes place from dispersed cities to large industrial agglomerations at high levels of trade freeness, but the reverse pattern obtains when trade freeness is low. Moreover, the model predicts a non-monotonic response of commuting behaviour when trade costs are reduced: if trade costs are continuously reduced from a prohibitive level, the extent of commuting first decreases and then increases.

The model also predicts that industry becomes more agglomerated when trade costs are reduced. These results are best understood in terms of the interaction of the four fundamental location forces, taking into account the feedback effects previously mentioned. The residence choice directly depends on local goods prices and housing prices. Therefore, the residence pattern reflects the fact that the supply linkage is the dominant force at low levels of trade freeness, while congestion in the housing sector dominates at high levels of trade freeness. The location of industry is directly determined by the wage differential which reflects the interaction of the market size effect and the competition effect. Since the demand linkage dominates at high levels of trade freeness and the competition effect dominates at low levels of trade freeness, industry is agglomerated when trade freeness is high and dispersed when trade freeness is low.

When commuting costs are positive but not prohibitive, the set of outcomes is richer. For one, a qualitatively similar set of results obtains as with zero commuting costs: dispersion of residences and agglomeration of industry at high levels of trade freeness and the reverse for low trade freeness, with the corresponding commuting patterns. However, 
this is not the only set of outcomes. Commuting costs also create a 'band of inaction' in the sense that no commuting takes place, unless the wage differential is large enough to compensate for the cost. Hence, at low and high levels of trade freeness, where in the model without commuting the agglomeration forces are smallest relative to the dispersion forces, residences and work places are (partly or fully) dispersed and there is no commuting activity. The range of trade costs where such a multiplicity of outcomes obtains shrinks as commuting costs are reduced and it is eliminated altogether when commuting costs are zero, as we have noted before.

\section{The model}

Our model extends the model of Pflüger and Südekum (2007) to include long-distance commuting. The model is a variant of the one developed by Forslid and Ottaviano (2003), which itself is an (almost) analytically solvable variant of Krugman's (1991) agglomeration model. In contrast to the Forslid-Ottaviano model, the Pflüger-Südekum model has a quasilinear upper-tier utility function (see also Pflüger, 2004) and an additional congestion force in the form of a fixed housing supply.

The economy consists of two regions called home $(H)$ and foreign $(F)$ which are ex ante symmetric in terms of preferences, technology, trade costs and labour endowments. Each region is endowed with $L$ units of land. There are two sectors. A manufacturing sector $(X)$ characterised by increasing returns, monopolistic competition and iceberg trade costs produces a composite of manufacturing varieties. A perfectly competitive sector labelled agriculture $(A)$ produces a homogeneous good with constant returns to scale. The A-good is traded without costs. This good is produced in both countries and is taken as the numéraire, i.e., its price is normalised to one.

Furthermore, there are two types of workers, skilled and unskilled labour. While unskilled labour is interregionally immobile, it is mobile between sectors, i.e., it can be employed in agriculture as well as manufacturing. Skilled workers on the other hand are mobile between regions but are employed only in manufacturing. The number (i.e., mass) of immobile unskilled workers in each region is denoted by $M$ and the total number (mass) of mobile workers is $K^{w}$. We will define $\rho \equiv M / K^{w}$ as the relative number of immobile workers.

Mobile skilled workers may either commute (at a round trip cost of $t \geq 0$ ) or migrate 
costlessly from one region to the other. Commuters buy the composite good completely in their region of residence. ${ }^{7}$ Thus commuters earn the wage of the region to which they commute, while consuming land and other goods at home.

Each consumer has a quasi-linear utility function given by

$U=C_{A}+\mu \ln C_{X}+\eta \ln C_{L}-[\mu(\ln \mu-1)+\eta(\ln \eta-1)], \quad$ with $C_{X}=\left(\int_{0}^{N} x_{i}^{\frac{\sigma-1}{\sigma}} d i\right)^{\frac{\sigma}{\sigma-1}}$,

where $\sigma>1$. $C_{A}$ is consumption of the numéraire good, $C_{L}$ is land consumption, $C_{X}$ is consumption of the manufacturing aggregate as in Dixit and Stiglitz (1977), $x_{i}$ is the quantity of variety $i, N$ is the mass of varieties produced in the manufacturing sector and $\sigma$ is the elasticity of substitution between any two manufacturing varieties. For an individual with net income $y$, the budget constraint is

$$
C_{A}+\int_{0}^{N} p_{i} x_{i} d i+Q C_{L}=y
$$

where $p_{i}$ denotes the consumer price of variety $i$ and $Q$ the price of land. Utility maximisation leads to the demand functions $x_{i}, C_{X}, C_{L}$ and $C_{A}$ and indirect utility $V$ :

$$
\begin{array}{r}
x_{i}=\mu P^{\sigma-1} p_{i}^{-\sigma}, \quad C_{X}=\mu / P, \quad C_{L}=\eta / Q, \quad C_{A}=y-\mu-\eta, \\
V=y-\mu \ln P-\eta \ln Q, \\
\text { where } P \equiv\left(\int_{0}^{N} p_{i}^{1-\sigma} d i\right)^{\frac{1}{1-\sigma}}
\end{array}
$$

is the perfect CES price index.

The numéraire good is produced with labour as the only input under a linear technology: $X_{A}=M_{A}$, where $M_{A}$ is labour input and $X_{A}$ is output. Perfect competition leads to marginal cost pricing in this sector. By implication, the agricultural wage is equal to the marginal product of labour, i.e. one.

Industrial firms produce with increasing returns to scale. Each firm requires one skilled worker and $c$ units of unskilled labour for each unit of output produced. Total costs of a firm which produces variety $i$ are $\pi+c X_{i}$, where $\pi$ is the wage of a skilled worker and $X_{i}$ is output of this firm.

Transport costs are of the iceberg type: only $1 / \tau$ of a unit bought in the other region can be used for consumption, with $\tau \geq 1$. Hence, indicating producer prices by a hat, in

\footnotetext{
${ }^{7}$ An extension would let mobile workers consume also at their place of work.
} 
the region where the variety is produced we have $p_{i}=\hat{p}_{i}$ and in the other region $p_{j}=\tau \hat{p}_{j}$. In the Dixit-Stiglitz model of monopolistic competition mill pricing is optimal. Since the model is symmetric, we will henceforth look at the home region only, the corresponding expressions for the foreign region being completely analogous. Profits of firm $i$ in home are

$$
\Pi_{i}^{H}=\left(\hat{p}_{i}-c\right) X_{i}^{H}+\left(\hat{p}_{i}-c\right) \tau X_{i}^{F}-\pi^{H},
$$

where total output is $X_{i}=X_{i}^{H}+\tau X_{i}^{F}$. Maximizing producer profits gives the optimal producer price of each variety:

$$
\hat{p}_{i}=\hat{p}=\frac{c \sigma}{\sigma-1} .
$$

We normalise marginal costs to $c=(\sigma-1) / \sigma$, which gives $\hat{p}=1$ and, hence, the consumer price index of the manufacturing good in home is

$$
P^{H}=\left(s_{K}+\phi\left(1-s_{K}\right)\right)^{\frac{1}{1-\sigma}},
$$

where $s_{K}$ stands for the share of skilled workers that is employed in the home region, and $1-s_{K}$ is the foreign region's share. $\phi \equiv \tau^{1-\sigma}$ stands for the degree of trade freeness with $0<\phi \leq 1$. Since each firm requires one skilled worker, the number of varieties is equal to the number of employed skilled workers: $N_{H}=s_{K} K^{w}$, where $N_{H}$ is the number of varieties produced in home. The world endowment $K^{w}$ has been normalised to one.

We can now complete the characterisation of the short-run equilibrium of the model. In the monopolistic competition framework, competition drives pure profits to zero and the reward to skilled workers is then equal to the operating profit. Using $\hat{p}=1$, equations (3) and (8), and denoting the number of skilled workers living in home by $s_{L}$, aggregate local demand for variety $i$ is

$$
X_{i}^{H}=\frac{\mu\left(\rho+s_{L}\right)}{s_{K}+\phi\left(1-s_{K}\right)} .
$$

This equation displays the difference between our model and models without commuting: in the latter, residents are also workers while in our model, skilled workers need not reside at their place of work. If individuals commute from $F$ to $H$ we have $s_{K}>s_{L}$, i.e., the share of domestic firms exceeds the share of skilled workers living in home.

Using (9) and applying the zero profit condition to (6), we find the wage of a skilled 
worker employed in the home region: ${ }^{8}$

$$
\pi^{H}\left(s_{L}, s_{K}, \phi\right)=\frac{\mu}{\sigma}\left(\frac{\rho+s_{L}}{s_{K}+\phi\left(1-s_{K}\right)}+\frac{\phi\left(\rho+1-s_{L}\right)}{1-s_{K}+\phi s_{K}}\right) .
$$

The wage differential across the two locations is of particular relevance in the ensuing analysis of commuting. It is given by

$$
\Delta \pi\left(s_{L}, s_{K}, \phi\right)=\frac{\mu(1-\phi)}{\sigma}\left(\frac{\rho+s_{L}}{s_{K}+\phi\left(1-s_{K}\right)}-\frac{\rho+1-s_{L}}{1-s_{K}+\phi s_{K}}\right) .
$$

where $\Delta \pi\left(s_{L}, s_{K}, \phi\right) \equiv \pi^{H}\left(s_{L}, s_{K}, \phi\right)-\pi^{F}\left(s_{L}, s_{K}, \phi\right)$.

The price of land is determined by the market equilibrium condition. Letting $L$ be the fixed supply of land, supply must equal aggregate demand, or:

$$
L=\frac{\eta\left(\rho+s_{L}\right) K^{w}}{Q^{H}} .
$$

We assume a three-stage model. At the first stage, individuals choose their place of residence. At the second stage, skilled workers choose whether or not to commute, for given residences. And finally, at the third stage, individuals work, buy and sell, for given residence and commuting patterns. This gives the short-run equilibrium we have just described, for given $s_{L}, s_{K}$.

As usual, we solve the game backwards. Using the short-run industry equilibrium and taking the location of residences as given, we therefore start by describing the equilibrium at the commuting stage. Afterwards, we analyse the residence choice stage.

At the second stage, skilled workers choose whether or not to commute, for given residences. This will determine the allocation of skilled workers across regions, for given $s_{L}$. Their choice is based upon a comparison of commuting costs and the skilled wage differential across locations $\Delta \pi\left(s_{L}, s_{K}, \phi\right)$. Commuting follows the myopic adjustment dynamics which is familiar from the Martin-Rogers (1995) model with mobile physical capital (see also Baldwin et al, 2003; Ottaviano and Thisse, 2004):

$$
\begin{aligned}
& \dot{s}_{K}>0 \text { if } \Delta \pi\left(s_{L}, s_{K}, \phi\right)>t \text { and } s_{K}<1 \\
& \dot{s}_{K}<0 \text { if } \Delta \pi\left(s_{L}, s_{K}, \phi\right)<-t \text { and } s_{K}>0 \\
& \dot{s}_{K}=0 \text { otherwise. }
\end{aligned}
$$

\footnotetext{
${ }^{8}$ Since our focus is on the allocation of workers and residences between regions in a process of trade integration which is symbolized by the trade freeness parameter $\phi$, we suppress the dependence of wages on the other parameters for convenience.
} 
When the skilled wage in $H$ net of commuting costs exceeds the foreign skilled wage, additional skilled workers commute from $F$ to $H$, as shown by (12). The converse case is in equation (13). If the skilled wage differential is smaller in absolute terms than the level of commuting costs, no additional commuting will occur as shown by (14). From $\Delta \pi\left(s_{K}, s_{K}, \phi\right)$ (which simply is $\Delta \pi\left(s_{L}, s_{K}, \phi\right)$ evaluated at $s_{L}=s_{K}$ ) the direction of commuting flows can be obtained. If $\Delta \pi\left(s_{K}, s_{K}, \phi\right)>t$, in equilibrium $s_{K}>s_{L}$, and $\Delta \pi\left(s_{K}, s_{K}, \phi\right)<-t, s_{K}<s_{L}$. If $-t \leq \Delta \pi\left(s_{K}, s_{K}, \phi\right) \leq t$, no commuting will occur. Hence, there is a band of inaction, very similar to the no delocation band in the model with mobile physical capital and relocation costs (see Baldwin et al, 2003).

In an interior equilibrium where some individuals commute from $F$ to $H$ we must have

$$
\Delta \pi\left(s_{L}, s_{K}, \phi\right)=t
$$

and likewise if commuting occurs from $H$ to $F$ it must be true that

$$
\Delta \pi\left(s_{L}, s_{K}, \phi\right)=-t
$$

Solving for the equilibrium will give the mass of skilled workers in $H$ as a function of the skilled population living in $H, s_{K}\left(s_{L}\right)$.

Using this in the first stage gives the utility differential for a skilled worker ${ }^{9}$

$$
\Delta V\left(s_{L}, \phi\right) \equiv V^{H}\left(s_{L}, s_{K}\left(s_{L}\right), \phi\right)-V^{F}\left(s_{L}, s_{K}\left(s_{L}\right), \phi\right) .
$$

The migration equation is given by the following myopic ad hoc dynamic equation which is standard in agglomeration models with mobile labour (Ottaviano and Thisse, 2004):

$$
\dot{s}_{L}=\Delta V\left(s_{L}, \phi\right) s_{L}\left(1-s_{L}\right),
$$

so that the share of skilled workers in Home increases when skilled labour realises higher utility in $H$ than in $F$. A spatial equilibrium arises at $s_{L} \in(0,1)$ when $\Delta V\left(s_{L}, \phi\right)=0$, or at $s_{L}=0$ when $\Delta V(0, \phi) \leq 0$, or at $s_{L}=1$ when $\Delta V(1, \phi) \geq 0$.

\section{Location and commuting choice}

\subsection{Prohibitive commuting costs}

As a benchmark, consider the case where commuting costs are prohibitively high. If $t \rightarrow \infty$, commuting will not occur. Individuals then live and work in the same region and $s_{K}=s_{L}$.

\footnotetext{
${ }^{9}$ The notation here is admittedly sloppy but convenient.
} 
For very low or very high trade costs, the only stable equilibrium is the symmetric equilibrium. There are two bifurcation points where a symmetric equilibrium loses (the break point $\phi_{B}^{1}$ ) and regains (the redispersion point $\phi_{B}^{2}$ ) local stability, respectively. ${ }^{10}$ These bifurcations are 'super-critical pitchforks' (see e.g. Grandmont, 1988 for an elaboration). As the level of trade freeness is gradually increased beyond the break point, two stable equilibria emerge, where one region contains an increasing share of industry. At $\phi_{S}^{1}$ (where $V^{H}=V^{F}$ for $s_{L}=0$ or $s_{L}=1$ ) all manufacturing activity just happens to be in one of the two regions. As the degree of trade freeness is increased further, partial agglomeration re-emerges at $\phi_{S}^{2}$ and a smooth redispersion sets in. Hence, $0<\phi_{B}^{1}<\phi_{S}^{1}<\phi_{S}^{2}<\phi_{B}^{2}<1$.

The location equilibria are determined by the trade-off between the model's agglomeration and dispersion forces, as is well known from other new economic geography models. First, there is a supply linkage. The region with the higher share of the mobile factor has a larger manufacturing sector, and therefore a lower manufacturing price index. Second, there is a demand linkage. Increasing the share of the mobile factor in one region implies a larger local market. This raises the relative profitability of this market and the skilled wage differential $\Delta \pi$. A stabilizing (dispersive) effect derives from the fact that, shifting firms from the foreign to the domestic region increases competition for given expenditures on domestic products, while lowering competition in the other region. Finally, there is a fourth effect, a further dispersion force, deriving from rising relative housing prices with rising relative resident population, which is independent of trade costs.

These forces will play an important role in the model with commuting as well. In particular, we will repeatedly use the fact that the sum of the demand linkage and competition effect is positive if and only if $\phi>\hat{\phi} \equiv \rho /(1+\rho)$, since $d \Delta \pi\left(s_{K}, s_{K}, \phi\right) / d s_{K}>0 \Leftrightarrow \phi>\hat{\phi}$ : when trade is relatively free, the demand linkage is stronger than the competition effect and, by implication, the larger region has the higher skilled wage rate; conversely, when trade freeness is low, the smaller region has the higher wage. ${ }^{11}$ Note that the threshold $\hat{\phi}$ rises with the share of the immobile unskilled, $\rho$, since it is the local demand of these which strengthens the (dispersive force) of the competition effect.

Figure 1 shows the difference in utility for varying $s_{L}$ and $\phi$. The parameters are $\eta=0.2, \mu=0.5, \sigma=3$, and $\rho=1$. The bifurcation diagram is shown in Figure 2 .

\footnotetext{
${ }^{10}$ Analytical details of this and the other results of this section are derived in Pflüger and Südekum (2007) and summarised in Appendix A.

${ }^{11}$ It can be shown that $\phi_{S}^{1}<\hat{\phi}<\phi_{S}^{2}$.
} 


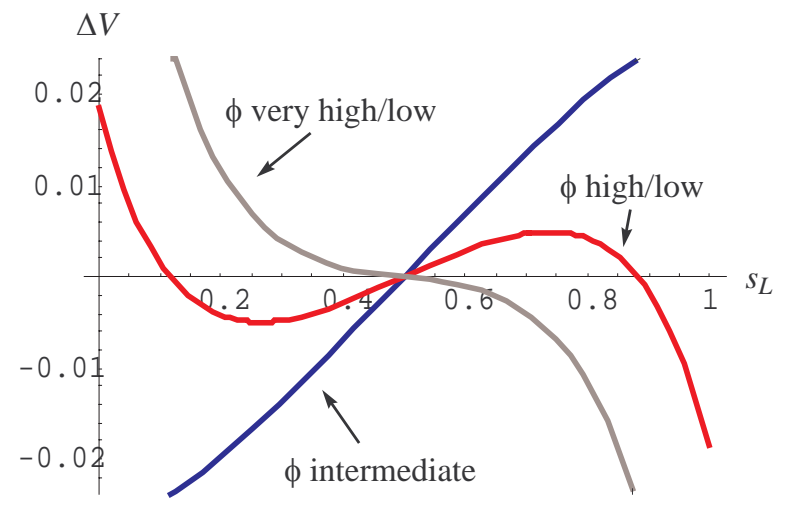

Figure 1: $\Delta V$ without long-distance commuting

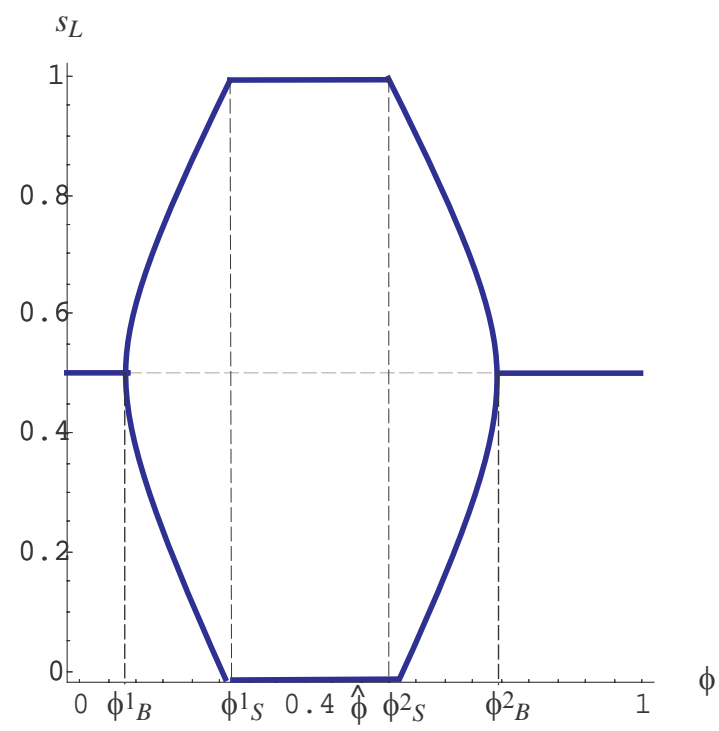

Figure 2: Bifurcation diagram without long-distance commuting 


\subsection{Equilibrium with zero commuting costs}

We are now interested in how location equilibria are affected by the possibility of commuting. If individuals commute in equilibrium, we have to distinguish between agglomeration of jobs and agglomeration of residences. We will proceed by first describing in detail the commuting equilibrium, i.e., for given residence choice we identify the pattern of commuting.

We note again that in the alternative interpretation of the model with capital mobility, commuting should be replaced by capital flows. Capital would then flow from the low-rent to the high-rent region, with the direction of net capital flows depending on trade freeness, as shown below for the case of commuting.

\subsubsection{Commuting equilibrium}

Since differences in net wages determine commuting patterns, commuting always occurs in one direction only. The pattern of commuting depends on the level of trade freeness which crucially affects the skilled wage differential across locations. In our analysis in the previous section, we have already identified the critical level $\hat{\phi} \equiv \rho /(1+\rho)$. If the level of trade freeness exceeds this threshold, the wage differential without commuting, $\Delta \pi^{o} \equiv \Delta \pi\left(s_{L}, s_{L}, \phi\right)$, is positive in the larger region. Hence, workers commute from the small to the large region when $\phi>\hat{\phi}$, and vice versa from the large to the small region when $\phi<\hat{\phi}$.

The incentive to commute, the commuting equilibrium and the skilled wage differential which results in such a commuting equilibrium (and which is relevant for the location equilibrium at the first stage) are illustrated in three part figure 3. Light grey curves depict the case where the level of trade freeness falls short of the critical level $\phi<\hat{\phi}$. The case where the level of trade freeness exceeds this critical level is illustrated by black curves.

Start with the case of high trade freeness $(\phi>\hat{\phi})$. The black line in the upper panel of figure 3 shows that $\Delta \pi\left(s_{L}, s_{L}, \phi\right)>0$ for $s_{K}=s_{L}>1 / 2$ and, hence, there is commuting into the domestic region; for $s_{K}=s_{L}<1 / 2$, there is commuting out of the domestic region. If the share of residents $s_{L}$ in the domestic region is neither too large nor too small, an interior commuting equilibrium obtains in which the wage differential is eliminated. From (11), we can solve for the equilibrium number of skilled workers in home, $\tilde{s}_{K}$, as a function 
of the skilled population living in home, $s_{L}$. For this equilibrium we have $\Delta \pi\left(s_{L}, \tilde{s}_{K}, \phi\right)=0$ :

$$
\tilde{s}_{K}\left(s_{L}, \phi\right)=\frac{1+\phi}{(1-\phi)(1+2 \rho)} s_{L}-\frac{\phi-(1-\phi) \rho}{(1+2 \rho)(1-\phi)} .
$$

This relationship is depicted by the (linear) upward-sloping part of the black curve in the middle panel of figure 3. If the domestic share of residents exceeds the threshold $\bar{s}_{L}$, everyone works in $H$, and if $s_{H}<\underline{s}_{L}$, everyone works in $F$. In both cases, a wage differential remains: when everyone works in home, $\Delta \pi\left(s_{L}, 1, \phi\right)>0$ and conversely, when everyone works in foreign, $\Delta \pi\left(s_{L}, 0, \phi\right)<0$. The threshold levels of an interior equilibrium at the third stage if $\phi>\hat{\phi}$ are

$$
\bar{s}_{L}=\frac{1+(1-\phi) \rho}{1+\phi}>\frac{1}{2} \quad \text { and } \quad \underline{s}_{L}=\frac{\phi-(1-\phi) \rho}{1+\phi}<\frac{1}{2} .
$$

Note that these threshold levels depend on $\phi$. If $\phi=1$, wages are independent of the location choice. Hence, $s_{K}$ is indeterminate (and the black curve in the middle panel of figure 3 vertical).

Turning to the case of low trade freeness $(\phi<\hat{\phi})$, the grey line in the upper panel of figure 3 indicates that $\Delta \pi\left(s_{L}, s_{L}, \phi\right)>0$ for $s_{L}=s_{K}<1 / 2$ and mobile workers commute into the domestic region for $s_{L}=s_{K}<1 / 2$ thereby eroding any wage differential. Conversely, for $s_{L}=s_{K}>1 / 2$ workers commute out of the domestic region. The commuting equilibrium is depicted by the grey upward-sloping line which is analytically given by (17). Figure 3 reveals that corner solutions $\left(s_{K}=0\right.$ or $s_{K}=1$ ) are ruled out when $\phi<\hat{\phi}$.

Drawing these two cases together, the mass of mobile workers in the home region is given by:

$$
s_{K}=\max \left[0, \min \left[\tilde{s}_{K}\left(s_{L}, \phi\right), 1\right]\right]
$$

for $\phi<1$ and $s_{K} \in[0,1]$ for $\phi=1$.

Observe that the relationship between $s_{K}$ and $s_{L}$ expressed in equations (17) and (19) and depicted in the middle panel of figure 3 is always non-negative for all levels of (noncomplete) trade freeness. Increasing the share of skilled residents in the domestic economy has a positive effect on the domestic industry share (less than one-for-one for low levels of trade freeness and more than proportionately for high trade freeness) in the commuting stage unless the domestic economy already houses all of industry.

To sum up, commuting occurs from the small to the large region when trade freeness is high and vice versa when trade freeness is low. To see why, recall that without commuting, the larger region has a higher wage only if trade freeness is high enough. When trade 

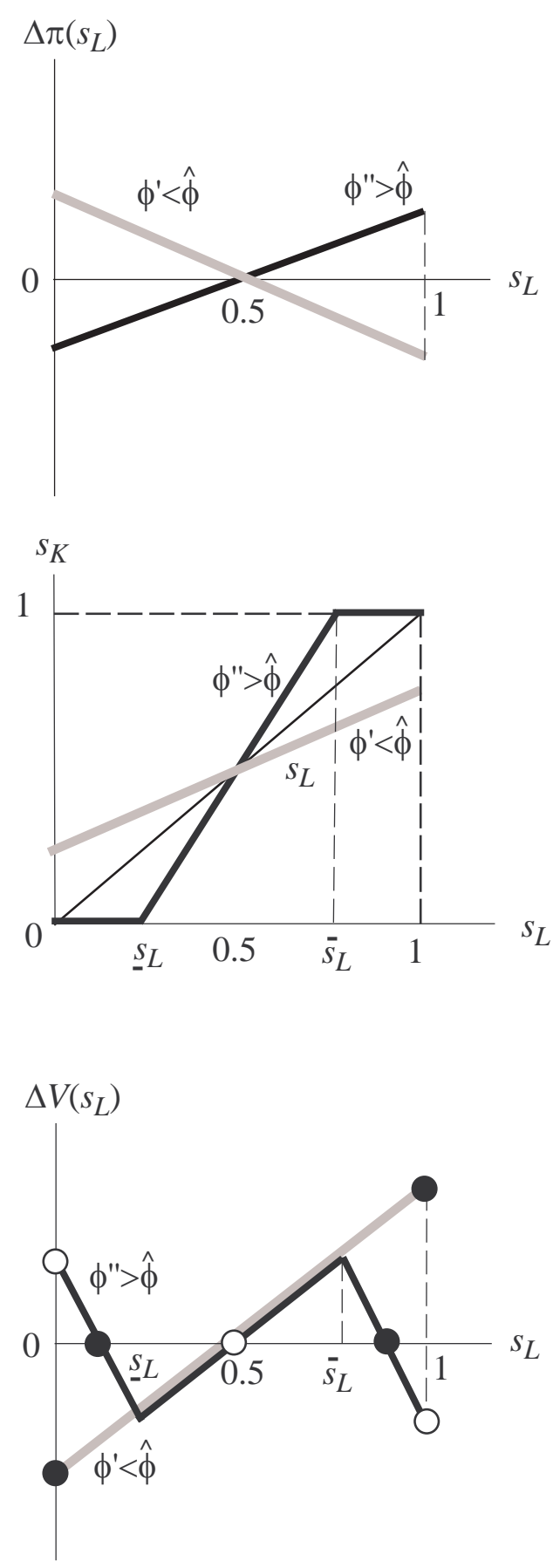

Figure 3: Commuting pattern with $t=0$ 
freeness is less than $\hat{\phi}$, wages are higher in the small region. Intuitively, although the larger region has a larger market, this effect is swamped by the fact that high trade costs reduce demand by the consumers of the small region. Therefore, firms have an incentive to serve the local market in the small region. With low enough trade freeness, this effect dominates the home market effect and, therefore, the smaller region will have higher skilled wages (see Krugman, 1991). Commuting therefore occurs from the large to the small region when trade is sufficiently closed.

\subsubsection{Location equilibrium}

Ultimately, we are interested in the effect of commuting on the location of residences. Therefore, we now describe the effect of commuting on the location equilibrium. In particular, we ask whether commuting leads to more or less agglomeration of residences than what we find in a world without long-distance commuting.

Let us rewrite the utility of an individual choosing to live in $H$ as

$$
V^{H}=\max \left\{\pi^{H}, \pi^{F}\right\}-\mu \ln P^{H}-\eta \ln Q^{H} .
$$

An analogous expression holds for an individual choosing to live in F. Equation (20) shows that the choice of residence will affect the price level of manufactured goods and the price of housing but not the wage, since costless commuting means individuals will work in the high-wage region regardless of their residence.

Therefore, the utility difference of a resident between living at home or in foreign can be written as:

$$
\begin{aligned}
\Delta V\left(s_{L}, \phi\right) & =\mu \ln \left(\frac{P^{F}}{P^{H}}\right)+\eta \ln \left(\frac{Q^{F}}{Q^{H}}\right) \\
& =\frac{\mu}{1-\sigma} \ln \left(\frac{1-s_{K}+\phi s_{K}}{s_{K}+\phi\left(1-s_{K}\right)}\right)+\eta \ln \left(\frac{\rho+1-s_{L}}{\rho+s_{L}}\right) .
\end{aligned}
$$

with $s_{K}=s_{K}\left(s_{L}, \phi\right)$ given by (19). The first term on the right of (21) shows the effect of the difference in the price levels between the regions, and the second term shows the effect of differences in housing prices. Again, note that the difference in wages disappears from the utility differential (21), since commuting means individuals will earn the same wage (namely, $\max \left\{\pi^{H}, \pi^{F}\right\}$ ) regardless of their place of residence.

Commuting changes the utility difference and therefore migration incentives through its effect on the price index of industrial goods (the housing market congestion does not depend on the mass of commuters since by assumptions firms occupy no space). 
Equation (21) shows the fundamental forces of agglomeration and dispersion in the model with commuting. Since differences of profits have disappeared from this equation, the usual demand linkage and competition effects of agglomeration running through the differences in profits are no longer operative. We are therefore left with the differences in housing prices and the supply linkage running through the price indices of industrial goods.

Looking at relative housing prices first, from (22) we have

$$
\frac{d \ln \left(Q^{F} / Q^{H}\right)}{d s_{L}}=-\frac{1+2 \rho}{\left(\rho+1-s_{L}\right)\left(\rho+s_{L}\right)}<0 .
$$

The housing market effect always deters agglomeration and is independent of trade freeness. $^{12}$

Proceeding likewise, from (22) we find the effect of varying $s_{L}$ on relative manufacturing prices. If $\phi=1$, consumer good prices are uniform across regions and independent of industry locations and residence choices: $P^{F} / P^{H}=1$. Otherwise:

$$
\begin{aligned}
\frac{d \ln \left(P^{F} / P^{H}\right)}{d s_{L}} & =\frac{d \ln \left(P^{F} / P^{H}\right)}{d s_{K}} \frac{d s_{K}}{d s_{L}} \\
& =\frac{-\left(1-\phi^{2}\right)}{(1-\sigma)\left(1-s_{K}+\phi s_{K}\right)\left(s_{K}+\phi\left(1-s_{K}\right)\right)} \frac{d s_{K}}{d s_{L}} .
\end{aligned}
$$

Using (17), we get for the interior commuting equilibrium:

$$
\frac{d \ln \left(P^{F} / P^{H}\right)}{d s_{L}}=-\frac{(1+2 \rho)}{(1-\sigma)\left(\rho+1-s_{L}\right)\left(\rho+s_{L}\right)}>0
$$

The cost-of-living effect would seem to depend on $\phi$. As shown by (25), increasing the number of firms in $H$ lowers the relative price index in $H$ and fall in relative prices is decreasing in $\phi$. However, this effect is just offset by the effect of a larger population on the number of firms through commuting, as shown by (26): when $\phi$ is low, prices decrease strongly with the number of firms but the number of firms increases less than proportionately with population since commuting occurs from the large to the small region; conversely with high $\phi$ prices decrease less with the number of firms but commuting implies that the number of firms increases more than proportionately with population.

\footnotetext{
${ }^{12}$ This follows because of quasilinear utility which implies that the demand for housing does not depend on income.
} 
Indeed, in the interior commuting equilibrium, the price effect is independent of the degree of trade freeness and (21) simplifies to

$$
\Delta V\left(s_{L}, \phi\right)=\left(\frac{\mu}{1-\sigma}+\eta\right) \ln \left(\frac{\rho+1-s_{L}}{\rho+s_{L}}\right) .
$$

Hence, we get

$$
\frac{d\left(\Delta V\left(s_{L}, \phi\right)\right)}{d s_{L}}=-\left(\frac{\mu}{1-\sigma}+\eta\right) \frac{1+2 \rho}{\left(\rho+1-s_{L}\right)\left(\rho+s_{L}\right)}>0
$$

where the inequality follows from a parameter restriction to restrict the congestion force associated with the housing sector - otherwise, symmetry would be the only equilibrium and commuting would therefore never occur (see Appendix A).

Interestingly, we find that the utility differential $\Delta V$ slopes upward in the interior commuting equilibrium regardless of the level of trade freeness (below $\phi=1$ ). Since this holds, in particular, at the symmetric allocation $s_{L}=1 / 2$, we have:

Proposition 1 When commuting costs are zero, a symmetric equilibrium is always unstable provided that trade costs are positive.

The lower panel of Figure 3 shows the utility differential and location equilibria with commuting for small and large $\phi{ }^{13}$ Symmetry $\left(s_{L}=1 / 2\right.$, and, therefore, $\left.s_{K}=1 / 2\right)$ is always an equilibrium, i.e. $V^{H}(1 / 2, \phi)=V^{F}(1 / 2, \phi)$. This location equilibrium is unstable for all non-zero levels of trade freeness, however, as we have just shown.

An interior commuting equilibrium always obtains for $\phi<\hat{\phi}$. Hence, the utility difference $\Delta V$ slopes upwards for all values $s_{L} \in[0,1]$. The grey line depicts this case and reveals that we have a unique unstable symmetric equilibrium and two stable equilibria with full agglomeration of residences.

An interior commuting equilibrium also obtains for $1>\phi>\hat{\phi}$ as long as $\underline{s}_{L} \leq s_{L} \leq \bar{s}_{L}$ (recall that $s_{K} \in(0,1)$ in this case). Hence, as depicted by the black line, the utility difference must also slope upwards in the vicinity of the symmetric equilibrium. However, at the point where everyone works in, say, $H$, an increase in the resident population has no more effect on the working population (this corresponds to $s_{L}>\bar{s}_{L}$ in the lower panel in Figure 3).

\footnotetext{
${ }^{13} \Delta V$ ist strictly concave for $s_{L} \in(0,1 / 2)$ and strictly convex for $s_{L} \in(1 / 2,1)$. For our set of parameters, the curve is close to linear.
} 
Setting $s_{K}=1$ in $(21)$ and differentiating for $\phi<1$ w.r.t. $s_{L}$ gives:

$$
\left.\frac{d \Delta V\left(s_{L}, \phi\right)}{d s_{L}}\right|_{s_{L}>\bar{s}_{L}}=-\frac{\eta(1+2 \rho)}{\left(\rho+s_{L}\right)\left(\rho+1-s_{L}\right)}<0 .
$$

Hence, the $\Delta V$ curve has a kink at $\bar{s}_{L}$ and slopes downward for $s_{L}>\bar{s}_{L}$. As $\phi$ gets larger, the utility differential must eventually get negative for large $s_{L}$ when trade is almost completely free. This is intuitive since when trade is completely free, location plays no role for the agglomeration of firms and the prices of industrial goods. The only effect of increasing population is then increased congestion in the housing market, which implies that as $\phi \rightarrow 1, \Delta V$ must be negative at $s_{L}=1$.

Hence, we can conclude that with sufficiently free trade a stable equilibrium with a partial agglomeration of residences emerges. By analogous reasoning, the same holds true at the point when everyone works in $F$.

Lemma 1 (i) There exists a level of trade freeness $\bar{\phi}$, with $\bar{\phi}>\hat{\phi}$, such that $\Delta V(1, \bar{\phi})=0$. (ii) For $1>\phi>\bar{\phi}$ and $s_{L}>1 / 2\left(s_{L}<1 / 2\right)$, there exists a unique $s_{L}$, with $s_{L}<1\left(s_{L}>0\right)$, such that $\Delta V\left(s_{L}, \phi\right)=0$ and $d \Delta V\left(s_{L}, \phi\right) / d s_{L}<0$. (iii) Furthermore, $\Delta V(1 / 2,1)=0$ and $d \Delta V(1 / 2,1) / d s_{L}<0$.

Proof. See Appendix B.

Lemma 1 directly implies the following result:

Proposition 2 Suppose commuting costs are zero. Then, (i) if $\phi<\bar{\phi}$, there exist an unstable symmetric equilibrium and two stable equilibria with full agglomeration, one with $s_{L}=1$ and one with $s_{L}=0$; (ii) if $1>\phi>\bar{\phi}>\hat{\phi}$, there exist an unstable symmetric equilibrium and two stable asymmetric equilibria with partial agglomeration of residences, one with $s_{L}>1 / 2$ and one with $s_{L}<1 / 2$; (iii) if $\phi=1$, there exists a unique stable symmetric equilibrium.

Figure 4 shows the bifurcation diagram, comparing the case of zero commuting costs (dark lines) with the case of prohibitive costs (light lines).

Proposition 2 together with (19) implies the following for the location of industry:

Corollary 1 With zero commuting costs, when $\phi<\hat{\phi}$, there is partial agglomeration of firms, with either $1 / 2<s_{K}<1$ or $1 / 2>s_{K}>0$; and when $1>\phi \geq \hat{\phi}$, there is complete agglomeration of firms with either $s_{K}=1$ or $s_{K}=0$. 


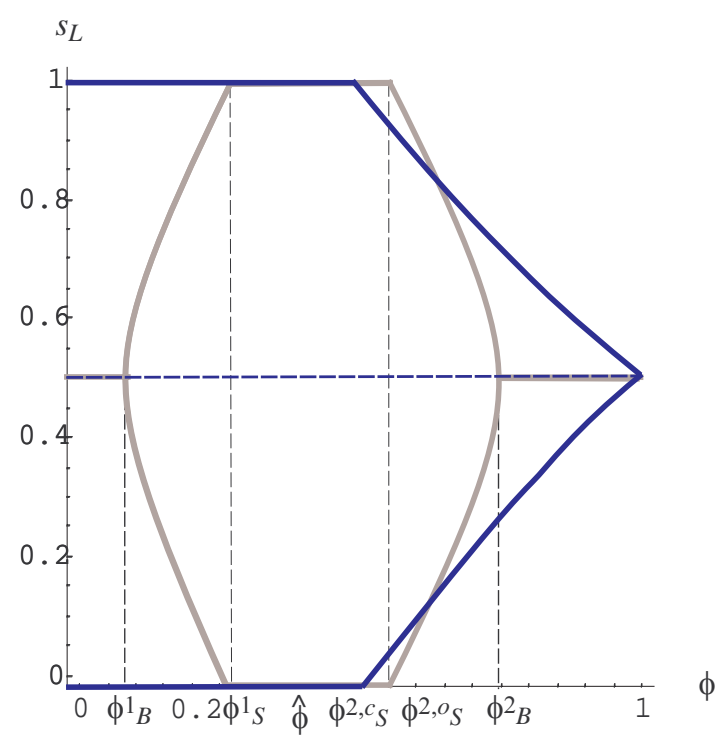

Figure 4: Bifurcation diagram with zero commuting costs

The bifurcation diagram for the location of industry with and without commuting is shown in Figure 5. Comparison with Figure 4 shows that there is an interesting contrast between agglomeration of residences and industry: while residences are agglomerated when trade is closed and dispersed when trade is free, conversely, industry is dispersed when trade is closed and agglomerated when trade is free. This reflects the workings of the fundamental agglomeration forces: the location of industry is governed solely by the wage differential. When trade is free (namely $\phi>\hat{\phi}$ ), wages are higher in the larger region and there is commuting from the small to the large region. Conversely, with relatively closed trade, wages are higher in the smaller region and commuting occurs from the large to the small region, i.e. industry is dispersed.

It is instructive, again, to look at the intuition for the diverging agglomeration of jobs and residences. Suppose that trade is closed. Then, for given residence locations, workers commute from the large to the small region, since the dominance of the competition effect ensures that wages are higher in the smaller region, as shown in the previous subsection. This implies that full agglomeration of jobs cannot be an equilibrium. However, the supply linkage dominates the congestion effect of the housing market so that full agglomeration of residences obtains while jobs are only partially agglomerated.

On the other hand, when trade is sufficiently free, the demand linkage dominates the 


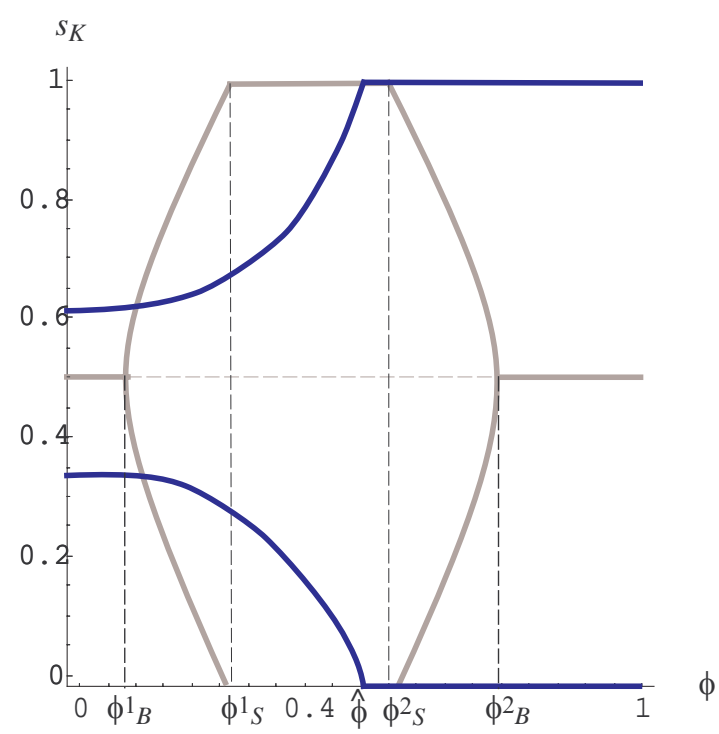

Figure 5: Bifurcation diagram $\left(s_{K}\right)$

competition effect so we will get agglomeration of jobs in the region with the larger population. When jobs are fully agglomerated in, say, region $H$, a symmetric allocation of residences is unstable. However, an increase in the resident population now reduces the utility differential between the large and small region, since with all jobs already in $H$, the only effect of increasing population is to increase congestion in housing markets. Hence, for sufficiently large $\phi$, we get stable equilibria with partial agglomeration of residences and full agglomeration of jobs.

Turning back to the location of residences, Figure 4 shows that for $\phi<\hat{\phi}$, we have unambiguously more agglomeration (of residences) with than without commuting. This is immediately clear, since only full agglomeration can be a stable equilibrium in this case.

For $1>\phi>\hat{\phi}$, we find more agglomeration with commuting when trade is sufficiently free. However, we find that with commuting, partial agglomeration emerges at lower trade freeness than without commuting. Hence, the effect of commuting on agglomeration depends on the level of trade freeness.

We prove in the Appendix that (a) the 'sustain' point $\phi_{S}^{2}$ - i.e., the point where we have full agglomeration of residences (and jobs) in $H$ - is lower with than without commuting, ${ }^{14}$

\footnotetext{
${ }^{14}$ The intuition is as follows: the sustain point with commuting equalises the dispersion force of the housing sector with the agglomeration force of the cost-of-living effect evaluated at $s_{L}=1$. Without
} 
while (b) in the commuting case the 'break' point $\phi_{B}^{2}$ - i.e., the point where the symmetric equilibrium becomes unstable - equals one and thus exceeds the corresponding point in the no-commuting case. The indices $c, o$ here refer to the equilibrium with and without commuting respectively.

Lemma 2 We have $\hat{\phi}<\phi_{S}^{2, o}<\phi_{S}^{2, c}<\phi_{B}^{2, o}<\phi_{B}^{2, c}=1$.

Proof. See Appendix B.

Lemma 2 obviuosly implies that there exists a $\tilde{\phi} \in\left[\phi_{S}^{2, c}, \phi_{B}^{2, o}\right]$ such that for all $\phi_{S}^{2, c}<$ $\phi<\tilde{\phi}$, we have $s_{L}^{P, c}<s_{L}^{P, o}$. Therefore, we have shown the following:

Proposition 3 Comparing commuting and no-commuting equilibria, we have more agglomeration of residences in the commuting case when trade freeness is low or high, while there is less agglomeration for intermediate trade freeness, that is, $s_{L}^{c} \leq s_{L}^{o}$ for all $\phi \in$ $\left[\phi_{S}^{2, c}, \tilde{\phi}\right]$ and $s_{L}^{c} \geq s_{L}^{o}$ for $\phi<\phi_{S}^{2, c}$ and $\phi \geq \phi_{B}^{2, o}$.

Note that from the ranking of the 'break' and 'sustain' points and the fact that the locus of partial agglomeration equilibria is concave with prohibitive commuting costs and convex with zero commuting costs (see Figure 4), we should be able to infer that there is more agglomeration of residences in the zero commuting cost case when $\phi$ is outside the interval $\phi \in\left[\phi_{S}^{2, c}, \tilde{\phi}\right]$. Numerical simulations show that there exists a wide range of parameters such that this is indeed the case. Summarising this discussion, we have:

Result 1 Suppose commuting costs are zero. Then, there is more agglomeration of residences than with prohibitive commuting costs except for intermediate levels of trade freeness, i.e., $\phi \in\left[\phi_{S}^{2, c}, \tilde{\phi}\right]$.

\subsection{Equilibrium with positive commuting costs}

We now analyse the case of positive commuting costs, proceeding like we did in the last subsection. However, since the algebra of the case with positive commuting costs is more involved, our main result rely on graphical representations and numerical simulations instead.

commuting, these two forces have the same strength (since $s_{K}=s_{L}=1$ ) but, since $\phi_{S}^{2, c}>\hat{\phi}$, nominal wages are higher in $H$ than in $F$ when $s_{L}=1$. Therefore, $\Delta V^{o}\left(1, \phi_{S}^{2, c}\right)>0$. 


\subsubsection{Commuting equilibrium}

The pattern of commuting again depends on the difference in skilled wages. However, due to commuting costs, no commuting occurs unless the wage differential is large enough. In particular, if $0<\Delta \pi\left(s_{L}, s_{L}, \phi\right)<t$ or $0>\Delta \pi\left(s_{L}, s_{L}, \phi\right)>-t$, no one will commute (in cases where commuting would occur without commuting costs).

The incentive to commute and the commuting equilibrium in such an equilibrium are portrayed in two part figure 6. This figure is analogous to Figure 3 and, in addition, takes the fixed commuting costs into account. These are depicted by the horizontal lines $t$ and $-t$ in the upper panel.

Start with the case of low trade freeness $(\phi<\hat{\phi})$ depicted by the grey lines in figure 6 . As in the case of zero commuting costs, no corner solutions can occur. There is a 'band of inaction' where no commuting occurs when $s_{L} \in\left(\check{s}_{L}^{\prime}, \hat{s}_{L}^{\prime}\right)$ where the wage differential without commuting (denoted $\Delta \pi^{o}$ in the following) is less than $t$ in absolute terms (for the thresholds see Appendix C). ${ }^{15}$ Outside this band, the mass of mobile workers $s_{K}\left(s_{L}, \phi\right)$ solves $\Delta \pi\left(s_{L}, s_{K}\right)=t$ (when commuting occurs from $F$ to $H$ ) or $\Delta \pi\left(s_{L}, s_{K}\right)=-t$ (when commuting occurs from $H$ to $F) .{ }^{16}$ Hence, the mass of mobile workers in the domestic region is given by $s_{K}\left(s_{L}\right)$ when $\left|\Delta \pi^{o}\right|>t$ and the wage differential is $t$. When $\left|\Delta \pi^{o}\right|<t$, the mass of mobile workers in the domestic region is given by $s_{L}$ and the wage differential is $\Delta \pi^{o}$.

The case of high trade freeness $(\phi>\hat{\phi})$ is depicted by the black lines. The upper panel shows that commuting is inhibited when the domestic share of residents is in the interval $\underline{s}_{L}^{\prime}, \bar{s}_{L}^{\prime}$. Hence, $s_{K}=s_{L}$ as shown in the lower panel.

Outside this band of inaction, the analysis is much the same as in the case of zero commuting costs. For the mass of mobile workers in the domestic region we obtain:

$$
s_{K}=\left\{\begin{array}{ccc}
s_{L} & \text { if } & \left|\Delta \pi^{o}\right|<t \\
\max \left[0, \min \left[\tilde{s}_{K}, 1\right]\right] & \text { if } & \left|\Delta \pi^{o}\right| \geq t
\end{array} .\right.
$$

The analytical relationships $\tilde{s}_{K}=s_{K}\left(s_{L}, \phi\right)$ in (30) which result in interior commuting equilibria are derived from $\Delta \pi\left(s_{L}, s_{K}, \phi\right)=t$ (commuting from $F$ to $H$ ) and from $\Delta \pi\left(s_{L}, s_{K}, \phi\right)=-t$ (commuting from $H$ to $F$ ), respectively. These relationships and the

\footnotetext{
${ }^{15}$ The various threshold levels here depend on parameters, in particular on $\phi$, but we suppress this dependence for ease of notation.

${ }^{16}$ The analytical relationships $s_{K}=s_{K}\left(s_{L}, \phi\right)$ which result in interior commuting equilibria and the threshold levels $\underline{s}_{L}^{\prime}, \bar{s}_{L}^{\prime}$ are derived in Appendix C.
} 
thresholds $\bar{s}_{L}^{\prime \prime}$ and $\underline{s}_{L}^{\prime \prime}$ which indicate the borderline values of the share of domestic residents at which corner solutions obtain in the commuting equilibrium, are analytically stated in Appendix C).

The skilled wage differential relevant for the residence choice (see below) corresponding to the solution of the commuting equilibrium is:

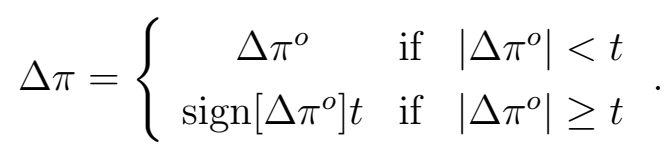

Inside the band of inaction where $\left|\Delta \pi^{o}\right|<t$ the skilled wages correspond to their values without commuting. Outside, the wage differential is equalised at $t$ (when $\Delta \pi>0$ ) or $-t$ (when $\Delta \pi<0$ ). This holds for an interior equilibrium. Again, the relevant wage differential also equals $t$ or $-t$ for a corner equilibrium: If everyone works in $H$ (which occurs when $\Delta \pi>0$ ), say, the wage obtained when living in $H$ is $\pi^{H}$ and that when living in $F$ is $\pi^{H}-t$, hence the differential $t$. Similarly, when everyone works in $F(\Delta \pi<0)$, the wage differential is $-t$.

At an interior commuting equilibrium, increasing $s_{L}$ increases the share of firms at home $s_{K}$ more than (less than) proportionately depending on whether $\phi>(<) \hat{\phi}$.

This completes our discussion of the equilibrium at the commuting stage.

\subsubsection{Location equilibrium}

As in the previous subsection, we analyse the effect of commuting on the utility differential of skilled workers. The utility differential which guides the location choice, takes the skilled wage differential and the equilibrium share of firms $s_{K}\left(s_{L}, \phi\right)$ in the commuting equilibrium into account (i.e. (30)). We now have:

$$
\Delta V\left(s_{L}, \phi\right)=\frac{\mu}{1-\sigma} \ln \left(\frac{1-s_{K}+\phi s_{K}}{s_{K}+\phi\left(1-s_{K}\right)}\right)+\eta \ln \left(\frac{\rho+1-s_{L}}{\rho+s_{L}}\right)+\operatorname{sign}\left[\Delta \pi^{o}\right] \min \left\{\left|\Delta \pi^{o}\right|, t\right\},
$$

where $s_{K}=s_{K}\left(s_{L}\right)$ is given by equations (A.4) and (A.8) of Appendix C for the interior solution.

From the analysis of the second stage around $s_{L}=1 / 2$ we know that, due to the presence of commuting costs, no commuting occurs (i.e. $s_{K}=s_{L}$ ) and the skilled wage differential is the same as with prohibitive commuting costs for all levels of trade freeness. Hence, long-distance commuting has no effect on the local stability of the symmetric 


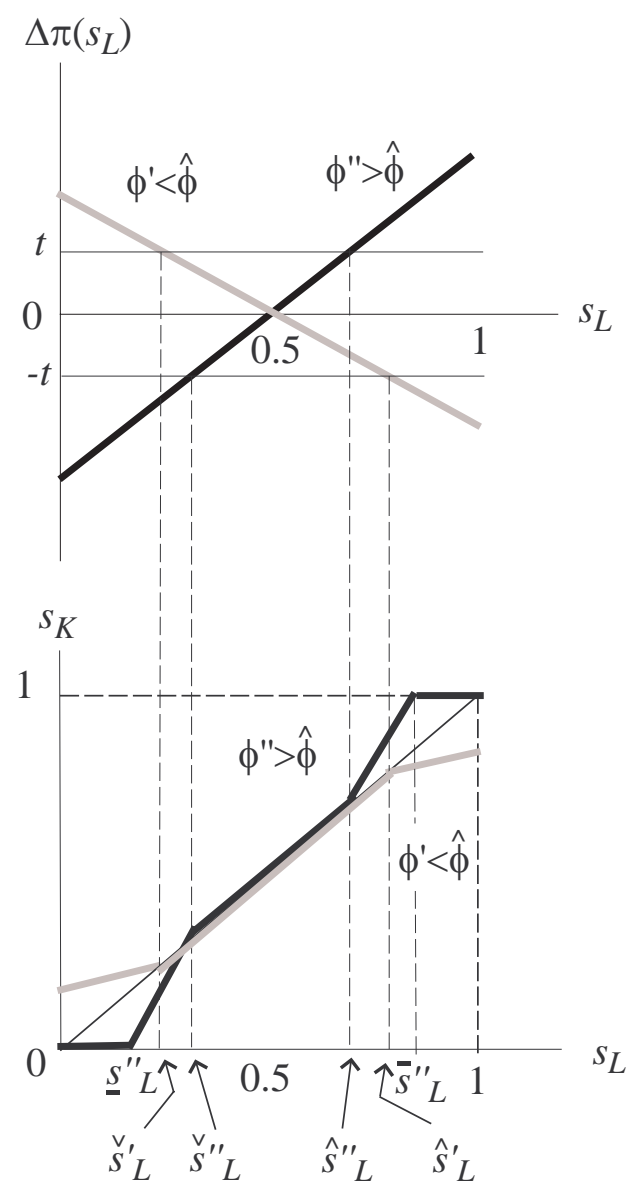

Figure 6: Commuting with $t>0$ 


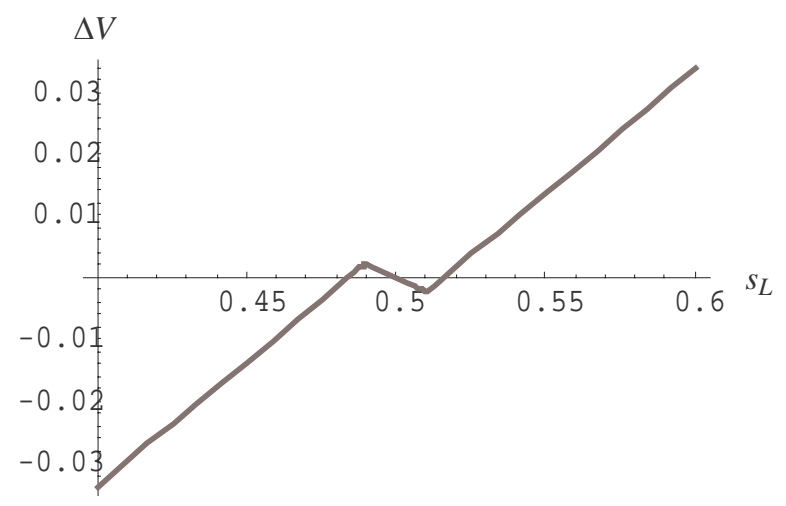

Figure 7: $\Delta V$ with $t>0$ and $\phi<\phi_{B}^{1}$.

equilibrium. This is depicted in figure 9, which superimposes the bifurcation diagram with positive commuting costs on the bifurcation diagram with prohibitive commuting costs (i.e. figure 2). This implies, of course, that the symmetric equilibrium is stable with commuting if and only if it is stable without commuting.

To explore the stability characteristics of other possible equilibria, we have to analyse the utility differential when we are outside the band on inaction. As we know from the commuting stage, the degree of trade freeness now matters.

Start with low levels of trade freeness, i.e. $\phi<\hat{\phi}$. For $s_{L} \notin\left(\check{s}_{L}^{\prime}, \hat{s}_{L}^{\prime}\right)$, an interior equilibrium must obtain, i.e., we have to take into account that $s_{K}=s_{K}\left(s_{L}, \phi\right)$ as given by (30). By the same argument as in the previous subsection, when $s_{K}=\tilde{s}_{K}$, it can be shown that $\Delta V$ must be upward sloping. An example for $\phi<\phi_{B}^{1}$ is shown in Figure 7 (The parameter values are $\eta=0.2, \mu=0.5, \sigma=2, \rho=1$ and $\phi=0.02.){ }^{17}$

When $\phi>\hat{\phi}$, we have to consider again that there may not be an interior solution for $s_{K}$ when individuals commute. As discussed before, around $s_{L}=1 / 2$ we always have the same utility differential as without commuting, since here the commuting cost is too large relative to the gain in net wages so that no one commutes. Then, when individuals commute, say, from $F$ to $H$ (which occurs when $s_{L}>1 / 2$ ), the utility differential slopes upward until $\tilde{s}_{K}=1$ when it starts to slope downward. Figure 8 shows an example when $\phi>\phi_{B}^{2}$. There are now three stable equilibria, one symmetric and two asymmetric. In addition, there are two unstable asymmetric equilibria with partial agglomeration. Furthermore, there is a level of trade freeness $\check{\phi}$ (with $\phi_{B}^{2}>\check{\phi}>\hat{\phi}$ ) where the two stable equilibria with

\footnotetext{
${ }^{17}$ Here and below, the critical levels $\phi_{B}^{1}$ and so on refer to the no-commuting case.
} 


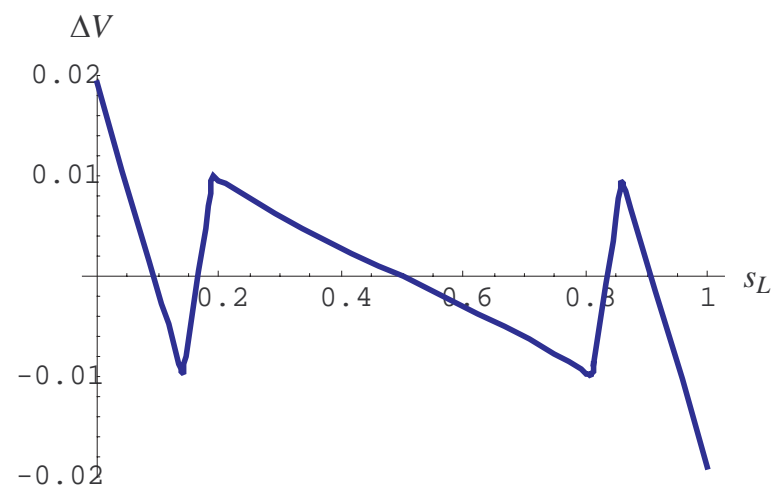

Figure 8: $\Delta V$ with $t>0$ and $\phi>\phi_{B}^{2}$.

partial agglomeration fall just within the band of inaction. Finally, when $\phi>{ }^{\overline{ }} \phi$, there is no commuting and symmetry is the only stable equilibrium.

Summarising this discussion, we have:

Result 2 Suppose commuting costs are positive but low. Then, there exists a wide range of parameter constellations such that (i) if $\phi>\overline{\bar{\phi}}$, there is a unique stable symmetric equilibrium; if $\overline{\bar{\phi}}>\phi>\phi_{B}^{2}$, there is a stable symmetric equilibrium and two stable asymmetric equilibria; if $\phi_{B}^{2}>\phi>\check{\phi}$, there are four stable asymmetric equilibria; and if $\check{\phi}>\phi>\hat{\phi}$, there are two stable asymmetric equilibria; (ii) if $\phi<\phi_{B}^{1}$, there is a stable symmetric equilibrium and two stable equilibria with full agglomeration where $s_{L}=0$ or $s_{L}=1$; if $\phi_{B}^{1}<\phi<\phi$, there are two stable asymmetric equilibria with partial agglomeration and two stable equilibria with full agglomeration; and if $\phi<\phi<\hat{\phi}$, there are two stable equilibria with full agglomeration.

The corresponding bifurcation diagram is shown in Figure 9.

Figure 10 shows the bifurcation diagram for the home share of industry, $s_{K}$. As in the case without commuting costs, industry is dispersed at low levels of trade freeness and agglomerated with high levels of trade freeness, in the case when commuting occurs. However, within the band of inaction, the share of industry is the same with and without commuting. Note that this implies that there may be multiple stable equilibria, including the equilibria without commuting.

It is instructive to compare the equilibria with different commuting costs. With prohibitive commuting costs, we have a bell-shaped bifurcation diagram. In the extreme case 


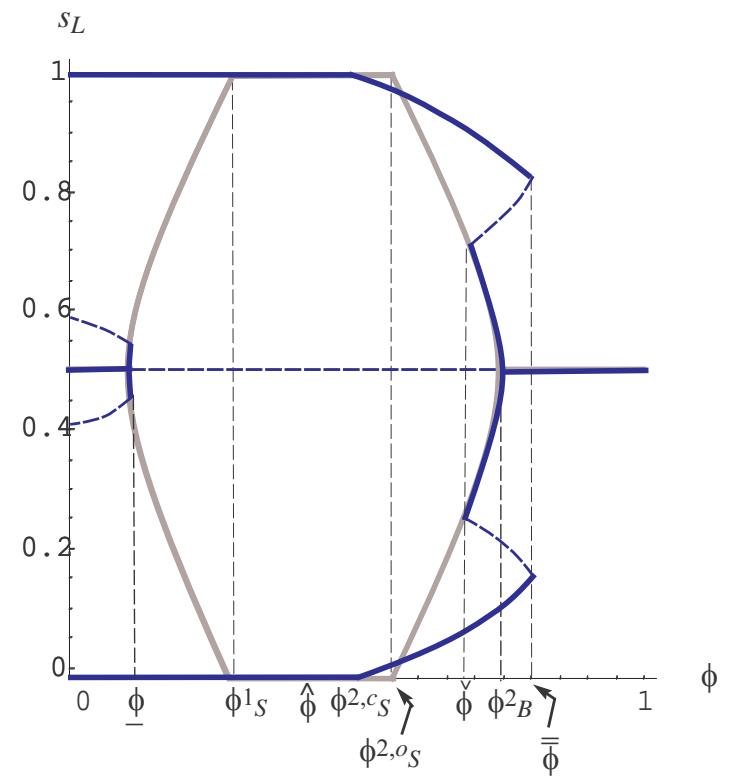

Figure 9: Bifurcation diagram with positive commuting costs

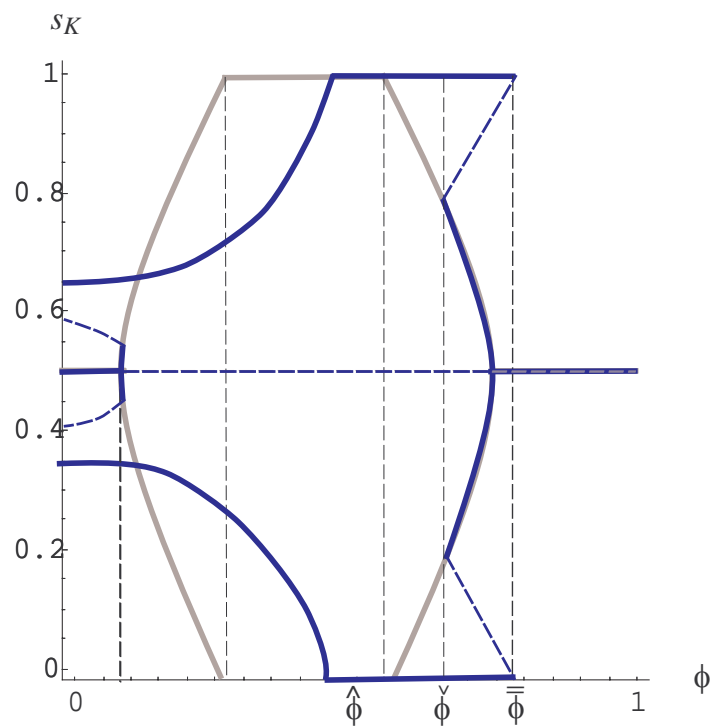

Figure 10: Bifurcation diagram (firm share) with positive commuting costs 
of zero commuting costs, the symmetric equilibrium is destabilised by commuting except at high levels of trade freeness where the location choice is dominated by housing costs. With positive (but low) commuting costs, the symmetric equilibrium regains its stability characteristics. However, further equilibria with partial or full agglomeration of location now emerge.

\section{Conclusion}

This paper provides a simple theory of geographical mobility which simultaneously explains people's choice of residences in space and the location of industry. Residences are chosen by individuals on the basis of the utilities they obtain across locations. The spatial pattern of industry is determined by the location decision of a scarce essential factor of production which seeks to obtain the highest possible economic return. In one application which we have highlighted in the exposition of our theory, this essential factor is the skill embedded in these households, which they may either provide at the location of residence they have chosen, or by way of commuting, at an alternative distant location. In an alternative interpretation of our theory, physical capital owned by households is the scarce essential factor. This capital may either be installed at the chosen location of residence or at the alternative distant location. In the first of these applications the scarcity rent derives in the form of high-skilled wages and the mobility costs are associated with commuting. In the second application, the return is in the form a capital rent and mobility may be hindered by capital relocation costs. Hence, apart from endogenising the residence choice, our theory comprehends the phenomena of commuting and physical capital mobility which we observe prominently in our age of mobility.

Because of feedback effects between residences and industry location which derive from market size and crowding effects and which depend on the interaction of trade costs, commuting costs or capital relocation costs, we obtain a non-trivial theory which provides a rich set of implications, some of which are in broad correspondence with the observed facts and some which merit further empirical investigation. For example, referring to the decline in trade costs, commuting costs and capital relocation costs, our theory is able to explain that long-distance commuting and foreign direct investment have increased and that industrial activity has become more concentrated both within as well as across countries. It should also be noted that our model features a multiplicity of stable equilibria 
when commuting costs or capital relocation costs are nonzero (but not so large as to prohibit movement). Due to a band of inaction created by these mobility costs, another prediction of our analysis is that dispersion of residences and industry is stable at low and high trade costs.

As in all new economic geography models, our results are driven by some particular assumptions concerning preferences, technologies and mobility costs. We believe, however, that our analysis, in making use of the agglomeration and dispersion forces that obtain across a wide variety of new economic geography models, is a useful starting place for analysing the joint determination of industry location and residence choices.

\section{Appendix}

\section{A The model without commuting}

Here we briefly present some parameter restrictions taken from Pflüger and Südekum (2007). In order to obtain two real bifurcation levels, $1+4 \sigma(\sigma-1)[1-\gamma(\sigma-1)]>0$ has to be fulfilled, where $\gamma=\eta / \mu$. A sufficient condition to fulfill this requirement which we assume to hold is $1-\gamma(\sigma-1)>0$. In order to rule out that the agglomerative forces become so strong that the symmetric equilibrium is unstable even at infinite trade costs, $[\rho /(\rho-1)-2 \rho](2 \rho+1) / \sigma<\gamma$ has to be satisfied (no-black-hole condition). A sufficient condition is $2 \rho>\sigma /(\sigma-1)$. Both sectors are only active after trade if $\rho \sigma /[(2 \rho+1)(\sigma-1)]>\mu$.

\section{B Zero commuting costs: Proofs}

Proof of Lemma 1. (i) If $\phi=\hat{\phi}, \Delta V(1, \phi)>0$. For $\phi>\hat{\phi}$ and $s_{L}>\bar{s}_{L}$,

$$
\Delta V\left(s_{L}, \phi\right)=\left(\frac{\mu}{1-\sigma}\right) \ln (\phi)+\eta \ln \left(\frac{\rho+1-s_{L}}{\rho+s_{L}}\right)+\Delta \pi\left(s_{L}, 1\right)
$$

If $\phi=1$, we get immediately

$$
\Delta V(1,1)=\eta \ln \left(\frac{\rho}{1+\rho}\right)<0 .
$$


Since $\Delta V(1, \phi)$ is continuous and decreasing in $\phi$, there exists a unique $\bar{\phi}>\hat{\phi}$, such that $\Delta V(1, \phi)=0$. (ii) Let $\phi>\hat{\phi}$. Obviously, $\Delta V\left(\bar{s}_{L}, \phi\right)>0$. Let $s_{L}>\bar{s}_{L} . \Delta V\left(s_{L}, \phi\right)$ is strictly concave. Hence, if $\phi>\bar{\phi}$, there exists exactly one $s_{L}$, with $1>s_{L}>\bar{s}_{L}$, such that $\Delta V\left(s_{L}, \phi\right)=0$. This $s_{L}$ fulfills $d \Delta V\left(s_{L}, \phi\right) / d s_{L}<0$. A similar argument holds true for $s_{L}<1 / 2$. (iii) $\Delta V\left(s_{L}, 1\right)=\eta \ln \left(Q^{F} / Q^{H}\right)$. The unique solution of $\Delta V\left(s_{L}, 1\right)=0$ is $s_{L}=1 / 2$, where $d \Delta V(1 / 2,1) / d s_{L}<0$.

Proof of Lemma 2. Note first that from the previous analysis, we know that the analogues of $\phi_{B}^{1, o}$ and $\phi_{S}^{1, o}$ do not exist, i.e., for $\phi<\hat{\phi}$ only full agglomeration is an equilibrium. Second, for the 'sustain points' we find $\phi_{S}^{2, c}<\phi_{S}^{2, o}$ : From (17), we know $s_{K}(1, \hat{\phi})=1$. From (21), we have

$$
\Delta V^{c}(1, \phi)=\frac{\mu}{1-\sigma} \ln \phi+\eta \ln \hat{\phi} .
$$

Setting $\Delta V^{c}(1, \phi)=0$ in $(\mathrm{A} .1)$ and solving gives

$$
\phi_{S}^{2, c}=\hat{\phi}^{\eta(\sigma-1) / \mu}>\hat{\phi}
$$

The difference

$$
\Delta V^{o}(1, \phi)-\Delta V^{c}(1, \phi)=\frac{\mu}{\sigma}(1-\phi)\left(1+\rho-\frac{\rho}{\phi}\right)
$$

is positive at $\phi=\phi_{S}^{2, c}$ since $\phi=\phi_{S}^{2, c}>\hat{\phi}$ (and thus $s_{K}(1, \phi)=1$ ), which establishes that $\phi_{S}^{2, o}>\phi_{S}^{2, c}$.

Finally, the 'break point' $\phi_{B}^{2, o}$ solves $d \Delta V\left(1 / 2, \phi_{B}^{2, o}\right) / d s_{L}=0$. With commuting, the symmetric equilibrium is never stable for $\phi<1$. At $\phi=1$, however, we have $\Delta V^{c}(1,1)=$ $\Delta V^{o}(1,1)=0$.

\section{Positive commuting costs}

From $\Delta \pi\left(s_{L}, s_{K}, \phi\right)=-t$, one obtains

$$
\begin{aligned}
s_{K}= & \frac{1}{2}-\frac{1}{2(1-\phi) \sigma t}\{\mu(1+2 \rho)(1-\phi) \\
& \left.-\sqrt{(1-\phi)^{2} \mu^{2}(1+2 \rho)^{2}-2 \mu\left(1-\phi^{2}\right) \sigma\left(1-2 s_{L}\right) t+\sigma^{2} t^{2}(1+\phi)^{2}}\right\} .
\end{aligned}
$$


Setting $s_{K}$ equal to 0 and $s_{L}$, respectively, yields

$$
\begin{aligned}
\underline{s}_{L}= & \frac{\mu(1-\phi)[\phi-(1-\phi) \rho]-\phi \sigma t}{\mu\left(1-\phi^{2}\right)}, \\
\check{s}_{L}^{\prime \prime}= & \frac{1}{2}+\frac{1}{2(1-\phi) \sigma t}\{2 \mu[\phi-(1-\phi) \rho] \\
& \left.-\sqrt{4 \mu^{2}[\phi-(1-\phi) \rho]^{2}+(1+\phi)^{2} \sigma^{2} t^{2}}\right\}, \\
\hat{s}_{L}^{\prime}= & \frac{1}{2}+\frac{1}{2(1-\phi) \sigma t}\{2 \mu[\phi-(1-\phi) \rho] \\
& \left.+\sqrt{4 \mu^{2}[\phi-(1-\phi) \rho]^{2}+(1+\phi)^{2} \sigma^{2} t^{2}}\right\} .
\end{aligned}
$$

From $\Delta \pi\left(s_{L}, s_{K}, \phi\right)=t$, one obtains

$$
\begin{aligned}
s_{K}= & \frac{1}{2}+\frac{1}{2(1-\phi) \sigma t}\{\mu(1+2 \rho)(1-\phi) \\
& \left.-\sqrt{(1-\phi)^{2} \mu^{2}(1+2 \rho)^{2}+2 \mu\left(1-\phi^{2}\right) \sigma\left(1-2 s_{L}\right) t+\sigma^{2} t^{2}(1+\phi)^{2}}\right\} .
\end{aligned}
$$

Setting $s_{K}$ equal to 1 and $s_{L}$, respectively, yields

$$
\begin{aligned}
\bar{s}_{L}= & \frac{\mu(1-\phi)[1+(1-\phi) \rho]+\phi \sigma t}{\mu\left(1-\phi^{2}\right)}, \\
\hat{s}_{L}^{\prime \prime}= & \frac{1}{2}-\frac{1}{2(1-\phi) \sigma t}\{2 \mu[\phi-(1-\phi) \rho] \\
& \left.-\sqrt{4 \mu^{2}[\phi-(1-\phi) \rho]^{2}+(1+\phi)^{2} \sigma^{2} t^{2}}\right\}, \\
\check{s}_{L}^{\prime}= & \frac{1}{2}-\frac{1}{2(1-\phi) \sigma t}\{2 \mu[\phi-(1-\phi) \rho] \\
& \left.+\sqrt{4 \mu^{2}[\phi-(1-\phi) \rho]^{2}+(1+\phi)^{2} \sigma^{2} t^{2}}\right\} .
\end{aligned}
$$

\section{References}

Baldwin, R., R. Forslid, P. Martin, G. Ottaviano and F. Robert-Nicoud (2003). Economic geography and public policy. Princeton University Press, Princeton and Oxford. 
Baldwin, R. and P. Martin (1999). Two waves of globalisation: Superficial similarities and fundamental differences. In H.Siebert (ed.), Globalisation and Labour, ch. 1, pp 3-59, Mohr, Tubingen.

Dixit, A. and J.E. Stiglitz (1977). Monopolistic competition and optimum product diversity. American Economic Review 67, 297-308.

Faini, R., J. de Melo and K. F. Zimmermann, eds. (1999) Migration. The Controversies and the Evidence. Cambridge University Press, Cambridge.

Forslid, R. and G. Ottaviano (2003). An analytically solvable core-periphery model. Journal of Economic Geography 3, 229-240.

Friedman, T. (1999). The Lexus and the Olive Tree. Farrar, Straus and Giroux.

Friedman, T. (2006). The World is Flat. Updated and Expanded Version. Farrar, Straus and Giroux.

Grandmont, J.-M. (1988). Non-linear difference equations, bifurcations and chaos: An introduction. Lecture Notes no. 5, IMSSS Economics Lecture Note Series, Stanford, CA.

Krugman, P. (1991). Increasing returns and economic geography. Journal of Political Economy 99, 483-499.

Krugman, P and R. Livas Elizondo. (1995). Trade policy and the third world metropolis. Journal of Development Economics 49, 137-150.

Martin, P. and C.A. Rogers (1995). Industrial location and public infrastructure. Journal of International Economics 39, 335-351.

Mathä, T. and L. Wintr (2007). Modelling commuting flows across bordering regions. Mimeo. Forthcoming in Applied Economic Letters.

MKW (2001). Scientific report on the mobility of cross-border workers within the EEA. Report for the European Commission, DG Employment and Social Affairs, MKW. Munich.

Murata, Y. and J.-F. Thisse (2005). A simple model of economic geography à la HelpmanTabuchi. Journal of Urban Economics 58, 137-155. 
OECD (2000) Employment outlook 2000. OECD, Paris.

OECD (2005) Employment outlook 2005. OECD, Paris.

Ogura, L.M. (2005). Urban growth controls and intercity commuting. Journal of Urban Economics 57, 371-390.

Ottaviano G. and J.-F. Thisse (2004). Agglomeration and economic geography. In: Henderson, J.V. and J.-F. Thisse (Eds.). Handbook of Regional and Urban Economics vol. 4, Elsevier, Amsterdam, 2563-2608.

Pflüger, M. (2004). A simple, analytically solvable Chamberlinian agglomeration model. Regional Science and Urban Economics 34, 565-573.

Pflüger, M. and J. Südekum (2007). Integration, agglomeration and welfare. Forthcoming, Journal of Urban Economics.

Statistisches Bundesamt (2005). Leben und Arbeiten in Deutschland: Ergebnisse des Mikrozensus 2004. Statistisches Bundesamt, Wiesbaden.

Tabuchi, T. (1998). Urban agglomeration and dispersion: A synthesis of Alonso and Krugman. Journal of Urban Econonomics 44, 333-351.

Tabuchi, T. and J.-F. Thisse (2005). Regional specialization, urban hierarchy and commuting costs. International Economic Review 47, 1259-1317.

Vermeulen, W. (2003). A model for Dutch commuting. CPB Report 2003/1. 